\title{
Adolescent girls' voices on enhancing their own productivity in Pakistan: Highlights 2019
}

\author{
Iram Kamran \\ Population Council \\ Tahira Parveen \\ Population Council \\ Rehan M. Niazi \\ Population Council
}

Follow this and additional works at: https://knowledgecommons.popcouncil.org/departments_sbsr-pgy

Part of the Demography, Population, and Ecology Commons, Family, Life Course, and Society Commons, Gender Equity in Education Commons, and the Inequality and Stratification Commons How does access to this work benefit you? Let us know!

\section{Recommended Citation}

Kamran, Iram, Tahira Parveen, and Rehan M. Niazi. 2019. "Adolescent girls' voices on enhancing their own productivity in Pakistan: Highlights 2019." Islamabad: Population Council. 


\section{Adolescent Girls' Voices on Enhancing their 0wn Productivity in Pakistan}

Highlights 2019

\section{Of the 11 million girls aged 15 to 19 years in Pakistan, nearly half (47 percent) are "not in education, employment, or marriage" (NEEM)}

This brief presents highlights from a qualitative study conducted in Punjab province of Pakistan to:

- Probe the lives, perspectives, and aspirations of NEEM girls (15-19 years) regarding education and involvement in economic activity

- Identify locally acceptable ways in which their lives may be positively transformed through access to education and safe and fair work opportunities.
The study districts included:

Faisalabad: one of the most developed districts in central Punjab

Kasur: a moderately developed district in central Punjab Rajanpur: one of the least developed districts in southern Punjab

We listened to 230 study participants through 42 in-depth interviews with NEEM girls (15-19 years); 20 focus group discussions (FGDs) with 190 girls (15-19 years); 10 FGDs with 86 mothers; 10 FGDs with 89 fathers; and 9 informal interviews with employers.

\section{Percentage of NEEM girls in study districts}

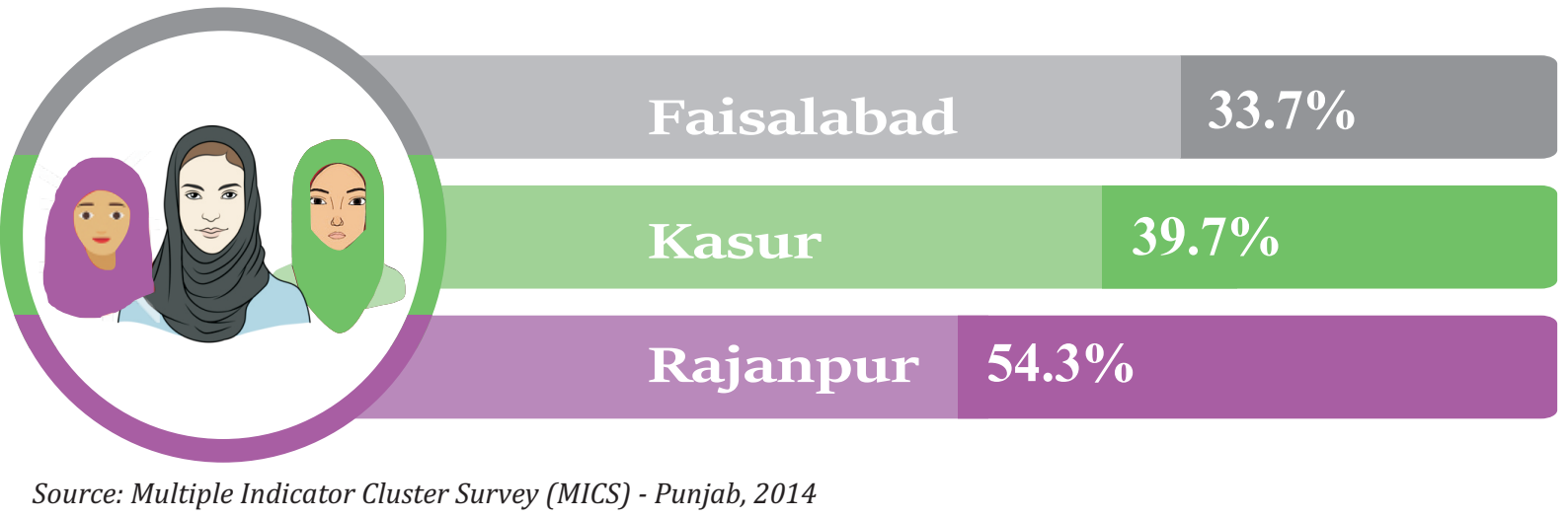

- NEEM girls are mostly poor and rural but also reside in urban areas and belong to the richest households.

- Rajanpur, in southern Punjab, has a higher proportion of NEEM girls than Kasur and Faisalabad, which are in central Punjab.

\section{A day in the life of a NEEM girl}

Percentage distribution of time (24 hours) across various activities among girl respondents in study districts

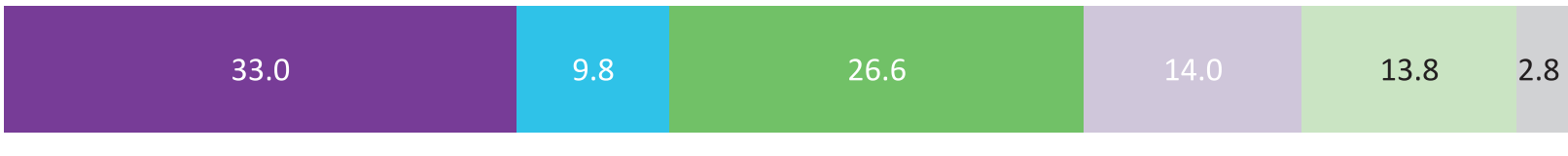

0

40

60

80

घ Sleeping time $\square$ Personal activities $\square$ Domestic duties $\square$ Unpaid work $\square$ Leisure/ spare time activities $\square$ Religious activities 


\section{Perspectives on Girls' Education}

\section{Most of the NEEM girls (197 out of 232) and their parents are very}

keen-even desperate - that they should resume their education.

\section{Most girls express strong feelings of sadness, deprivation, and a sense of inferiority at not being able to go to school.}

They are acutely aware that leaving school has put their life on a negative trajectory, which they feel powerless to change.

\section{"Shattered Hopes"}

My school fees were never an issue; everyone helped because they knew how passionate I was about studies. But our class consisted mostly of boys. Even our teachers were mostly male...I felt very shy. When I mentioned this, my parents pressured me to leave the school.

I wanted to earn for myself and my family but now all of my dreams are shattered.

I did not eat for days... My mother consoled me and advised me to help out at home and in the field since I had nothing left to do. Now I am just an ordinary girl who has lost hope. 16 years old girl from rural Rajanpur.

\section{Girls confront a series of challenges-at home, on the way to school, and in school-that compel them to drop out}

The school is about 4 miles from here-too far for us to drop girls and bring them back. We don't want to send our girls to school alone. Father of a 16 years old girl from rural Faisalabad

She (the teacher) used to make us wash the toilets and clean the floors and the rooms. 19 years old girl from urban Rajanpur

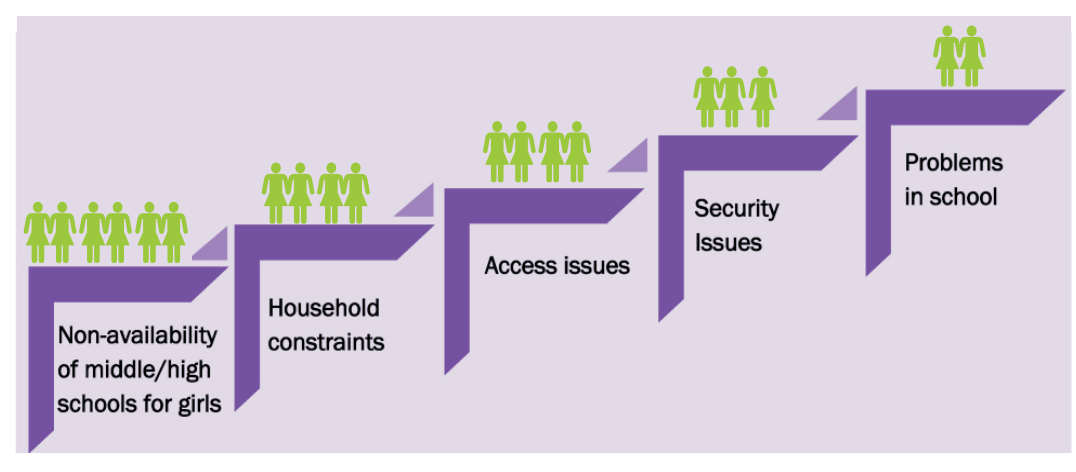

Boys' reasons for dropping out differ greatly from those of girls

Girls

Boys
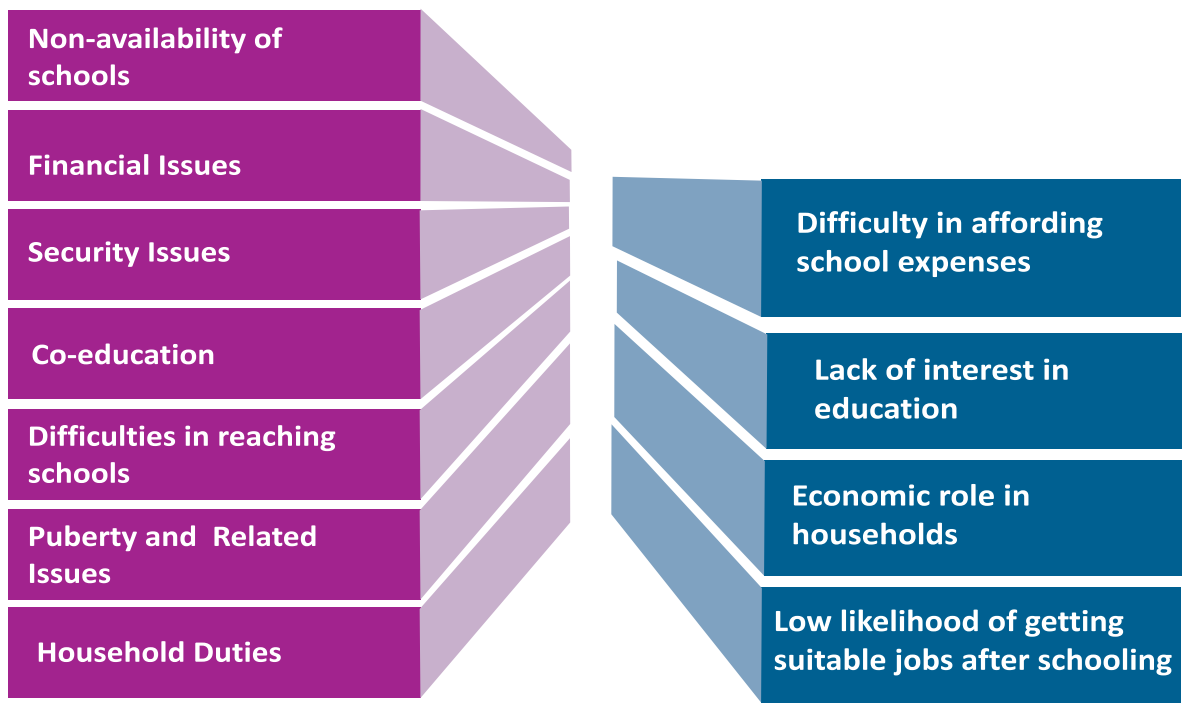


\section{Perspectives on Girls' Employment}

While education is viewed very positively in all communities, girls' participation in paid work is seen as more controversial and awkward involving significant social risk.

People make up stories, and I don't want to hear their talk....Yes, I want to earn and work on my own but the environment here does not allow it. 17 years old girl from rural Kasur

\section{Why NEEM girls do not work outside?}

The matter of unmarried females' going out to work is far more complex than their attending school.

- $\quad$ Parents worry about social risks, i.e., gossip and scandal due to working with men.

- There are limited or no opportunities to train or work within the community (especially for less educated girls).

- Outside their communities, girls are at risk of sexual harassment or worse.

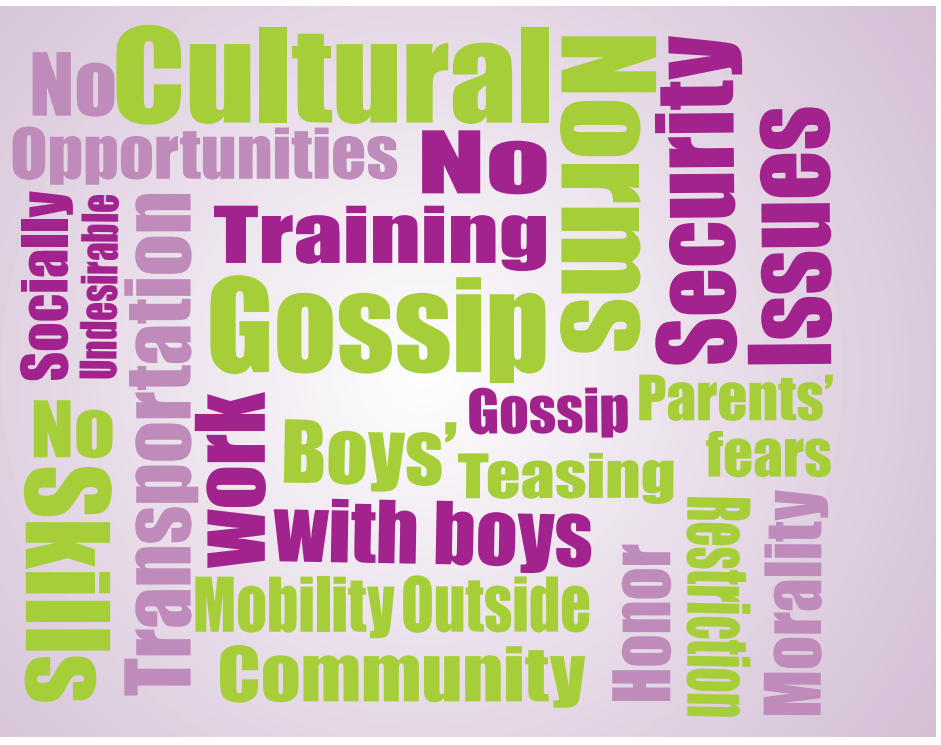

\section{What kind of work could NEEM girls do?}

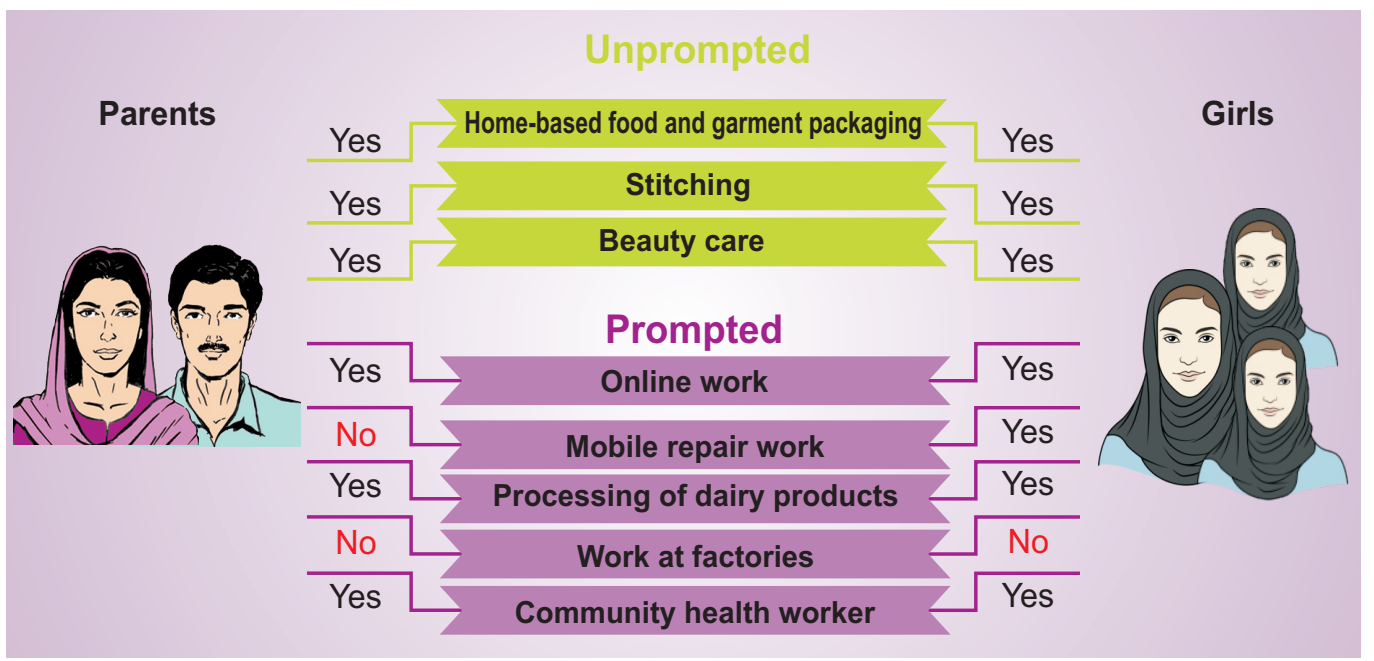

The girls will not do mobile repair work. Here, in our village, people even accuse mothers (of misuse of mobile phones), and you are talking about girls repairing mobiles for different people and boys? They can't do that. Mother of a 19 years old girl from rural Faisalabad

\section{What would persuade parents of NEEM girls to let their daughters work?}

\section{Parents are willing to let their girls:}

- Get trained within the community, in a gendersegregated setting; and
- Get employed, provided the workplace is respectful for girls and either located within the community, or safely accessible through transportation arranged by the employer. 


\section{Conclusions and Recommendations}

Conclusions: NEEM girls don't want to and need not be left behind. On the whole, Interventions to educate them would be enthusiastically welcomed by the girls as well as their parents and communities. Measures to improve their participation in paid work would be considered and accepted if practical and responsive to cultural sensitivities.

Recommendations: Based on the study's findings and programming experience, we suggest the following measures to expand opportunities for NEEM girls:

\section{To enroll and keep NEEM girls in school:}

Set up more public secondary schools for girls

Invest in reliable school bus services in

under-served areas

Provide cash and food incentives to girls' households to send them to school

Make co-educational schools more girl-friendly

Ensure that schools offer a socially and psychologically safe environment

Introduce accelerated programs for older out-of-school girls and remedial programs for struggling students

Introduce flexible school timings and calendars to cater to working children

Explore distance learning and non-formal education options for girls who cannot enroll.
To improve NEEM girls' participation in paid work:

Build vocational skills for both home-based work and local employment

Conduct female-led training programs with input from vocational training institutions and industry leaders

Nurture cottage industries and build girls' entrepreneurship skills and links with the market

Provide girls safe work environments as well as transportation

Base all livelihood interventions for girls on specialized market assessments with community participation.

\section{For long-term success, implementers should:}

* Address practical needs in a way that also meets strategic gender needs, with a vision for changing the norms that perpetuate gender inequality and lead to adolescent girls' marginalization;

* Ensure community leadership of interventions, especially participation of parents and women;

* Elicit the support of religious leaders and mass media for girls' rights and against gender-based violence; and

* Adopt an implementation approach to build concrete evidence of what works to empower girls in Pakistan.

\section{POPULATION}

\section{COUNCIL}

Ideas. Evidence. Impact.

\section{Copyrights}

Materials from this publication may be quoted or reproduced with due

acknowledgement of Population Council, Pakistan.

\section{Credits}

This brief is written by Iram Kamran, Tahira Parveen, and Rehan Niazi, and reviewed by Dr. Zeba A. Sathar, all from the Population Council, Pakistan office. It is edited by Kiren Khan and designed by Ali Ammad. 